\title{
The Application of Digital Storytelling to Higher Vocational College English Teaching Based on “Three-multi” Learning
}

\author{
ZHANG Lin-lin \\ Basic Teaching Department, Jilin Railway Technology College, Jihua Road No.666, Yongji Economic \\ Development Zone, Jilin, Jilin ,China132200
}

\begin{abstract}
In light of learning theory, teaching taxonomy and education policy, this paper aims to establish a teaching framework based on "three-multi" learning to apply digital storytelling to higher vocational college English teaching.

Key words: Digital Storytelling; “three-multi” Learning; Higher Vocational College English Teaching
\end{abstract}

Supporting Project: The paper was supported by "the $13^{\text {th }}$ Five-Year" Social Science Key Project of Education Bureau of Jilin Province (Grant No. JJKH20170406SK ).

\section{Introduction}

The development of information and communication technology enriched the learning environment, learning model and learning medium , which resulted in changes of English learning. Therefore, English teachers in higher vocational colleges are facing the great challenge of utilizing the plentiful learning resources to help students to achieve optimized English learning effect. According to the revised Bloom's Taxonomy, “creating” is the highest learning. Aiming at that target, English teachers in higher vocational colleges need to take account of learning theory, teaching taxonomy and education policy to establish a teaching framework that accommodates to English learning changes.

\section{2 “Three-multi” Learning}

Learning is the basic function of human brain. Educators made a lot of researches to study learning activity and got different understanding of learning. With the development of information technology, learning enjoys characteristics of digital era. Thus, researchers considered such factors as e-learning, digital learning, smart learning and social platform learning in their understanding of learning. Our understanding of learning should be developed with era.

Professor Gu Yueguo of Institute of Linguistics CASS regards multi-model learning through multi-media in multi-environments as the main learning model for human living in internet era. Professor Gu refers to this learning model as "Three-multi” learning. "Multi-environment" means that learning can be achieved at any place, such as classroom, library, dorm, home and various virtual environments. "Multi-media" refers to such information communicating media as book, body, internet, video, music, smart phone and social platform. "Multi-model” is various practice models of learning communication, including text, image, action, language, word type and layout.

“Three-multi” learning requires learners to take advantage of different senses through multi-media to transfer sources and motivate interaction between learners and environments. As a new learning model, "Three-multi" learning enjoys the common characteristics and rules of human learning activities.

\section{English Teaching}

English teaching in China began in the late nineteenth century, the Tongwen Guan in Peking was the first school taught English. After the Revolution of 1911, English teaching extended in missionary schools and thirteen Christian colleges. At the beginning of the establishment of People's Republic of China, foreign language teaching attached importance to Russian, English 
teaching was dying out. In 1978, China announced Reform and Open Policy, which was accompanied by the revival of English teaching. Almost all the middle schools and colleges in China opened English course. In 2001, the Bureau of Education in China lowered the age at which English is taught. Thus, English course covered all the primary and middle schools as well as colleges. The teaching targets of English varied with different eras, English teachers should consider learning and teaching experience of expertise so as to establish teaching framework to meet the requirement of learning model of different eras.

\section{English Teaching Framework Based on "Three-multi” Learning}

\subsection{The enlightenment of learning theory}

Various learning theory provide us with a lot of enlightenment. Behaviorist theorists believe repetitive practice is necessary for learning and stimuli from outside world have great effect on learning behavior. English teachers can use behaviorism when they arrange memory or practice assignments, reward and punish student learning behaviors(verbal reinforcement, bonus points and gifts). Cognitive learning theory disclosed that learner plays the most important part in learning process and only those information attracted learner and thought about by the learner can form long term memory in learner's brain. English teachers can apply cognitive theory when they select attractive information, associate new content with something known and design thought-provoking tasks(discussion, summarization and problem solving). Constructivist theorists believe learning is an active constructive process by learner, the outcome of learning is established on the basis of learner's own former experience and knowledge. English teachers can refer to constructivism when they arrange learner-centered learning tasks(group work and individual presentation). Social learning theory laid emphasis on interaction between learning and environment, other individual's influence. In accordance with that, English teachers should design interactive tasks and use model learning.

\subsection{The inspiration of teaching taxonomy}

Educators from home and abroad provided us with a lot of teaching models based on teaching practice, which offered precious reference for English teaching. The most popularized one is Bloom's Taxonomy, which was originally put forward by American psychologist Benjamin Samuel Bloom in 1956. Focusing on "learning in action”, Bloom's Taxonomy organized learning activities according to six different categories. The first category is knowledge, which is the lowest level of learning. The second level is called comprehension. Students can demonstrate basic understanding of what was communicated in this level. Bloom's third level is application, when students make use of abstract concepts and use them in a concrete of simulated situation. Analysis is the fourth level. Here students can break down information for greater understanding and they begin to put it all in context. The fifth level is synthesis, when students are connecting various elements of information to build new knowledge. The highest level of learning is evaluation, when students are judging the value of new knowledge. Like other teaching model, Bloom's Taxonomy is not perfect. So in 2001, Bloom's student Lorin Anderson revised it so that it could better serve for teaching. The revised version use verbs to describe and categorize learning behaviors, put "evaluate" to the fifth level and replace "synthesis” with “create” as the highest level of learning. From Bloom's Taxonomy, English teachers can learn that English teaching should be carried out by "doing”, "evaluate" is an important factor of and the highest teaching target is to help students to create something new.

4.3 The guideline of educational policy

The national educational policies laid a constructive foundation for English teaching. Higher Vocational College English Curriculum Basic Requirement (for Trial Implementation enacted by Higher Education Department of Education Ministry pointed out in higher vocational college 
English teaching, attention should be paid to cultivate English application and communication in real life, introduce such modernized teaching method as multi-media and internet technology in English teaching, and motivate students interest in English autonomous learning. Furthermore, the Notice of National Education Development Plan in the $13^{\text {th }}$ Five-year issued by the State Council stated that cultural exchanges between China and foreign countries should be strengthened in general, including promoting language communication with other countries worldwide and developing ability to tell Chinese stories and communicate Chinese ideas.

In all, learning theories, teaching model and educational policy provided us with principal basis and directional guide for constructing higher vocational college English teaching framework on the basis of "Three-multi" learning.

\subsection{English Teaching Framework Based On “Three-multi” Learning}

Computer and internet as well as related information technology development resulted in the “Three-multi” learning, which inevitably led to the changes of English learning. These changes urged English teachers to take into consideration of learning theories, teaching model and educational policy in order to carry out English teaching matching “Three-multi” learning.

Before the class

With the guidance of teacher, students are supposed to receive multi-model learning materials through various information communication media in different environment and complete basic English knowledge study including words and expressions, sentence patterns, reading skills and translation skills by way of listening, reading and memorizing. Those leaning materials include teaching script, PPT courseware and micro lecture video covering video, text, image, movement, sound, video, type and space. Various information communication media involve in text book, language, writing, video, smart phone and internet. Different environment refers to any place students can learn, such as classroom, home, dormitory, library and social community.

In the class

With teacher's instruction and classmates' assistance, students are expected to finish the knowledge practice process. That is, students complete multi-model English application practice containing text, sound and movement in the form of sample study, thinking, question-answering, summarizing, communication and outline though blackboard, projector, language, body and writing in the classroom.

After the class

Students realize language practice and reflection independently. They autonomously complete English innovative practice and learning assessment. They need create multi-model English work containing text, image, movement, voice, video and space in such environment as classroom, home, dorm, library and social community. Then, students release and present the work by language, writing, sound, video, smart phone and internet communication tools. Last, they receive multi-model teacher assessment and pal assessment through multi-media, meanwhile finish self-assessment.

English teaching framework based on "Three-multi” learning presents in multi-model forms through multi-media in multi-environment. It aims to establish autonomous learning ability cultivation framework for students by the aid of modern information technology means with the English practice task in order to improve students English practical application ability and guide the students to complete innovative practice. 


\section{English Teaching Framework Based on “Three-multi” Learning}

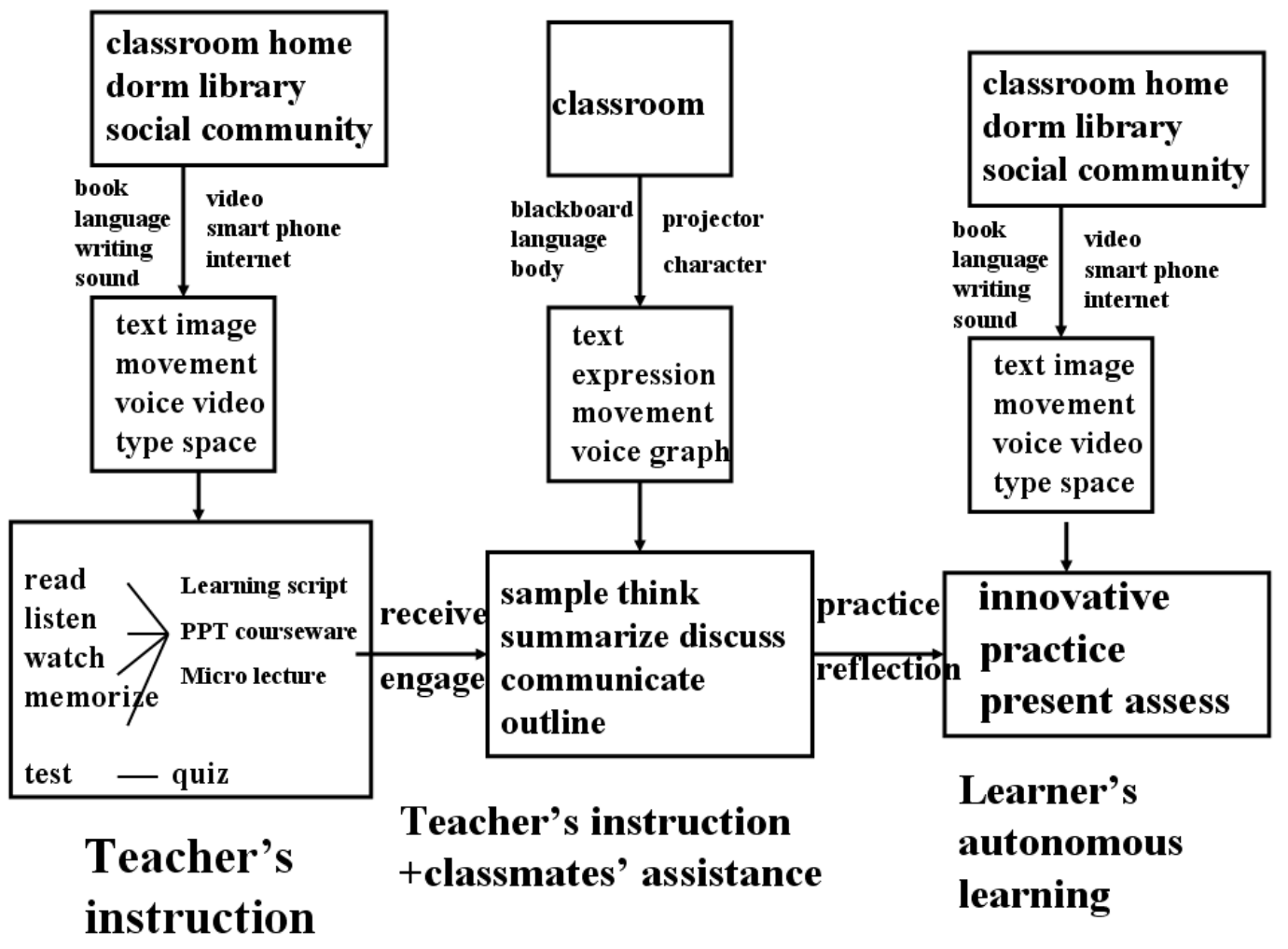

\section{Digital strory-telling}

Many researchers have attempted to define "Digital Storytelling”. In general, these definitions all involve around the idea of combining the art of telling stories with variety of multimedia, such as images, audio, and video to present information on a specific topic. Digital storytelling can help students to autonomously create multi-model English practice work through various information technology means in different environment, and then release their works though internet. Therefore, applying digital storytelling to English teaching can meet the demand of innovative practice on the basis of "Three-multi" learning as well as teaching target.

\section{Summary}

Internet and information technology changed the way of human learning, making it possible for people to learn at any time and place through any media in any form of model. These changes make it convenient to realize the highest learning. Digital storytelling provides good choice for higher vocational college English teachers to guide students to finish English innovative practice work autonomously in accordance with English teaching framework based on "Three-multi" learning.

\section{References}

[1] Anderson, L. W., \& Krathwohl, D. R.. A Taxonomy for learning, teaching , and assessing:a revision of Bloom's taxonomy of educational objective. [M]. New York: Longman,2001.

[2] Bloom, B.S. Taxonomy of educational objectives: The classification of educational goals: Handbook I, cognitive domain. [M]. New York: Longman,1956.

[ 3 ] Bandura, A. Social Learning Theory [M]. New York: General Learning Press ,1977.

[ 4 ] George Seimens. Connectivism: A Learning Theory for the Digital Age [J]. December 12, 2004 【EB、OL】 http://www.itdl.org/journal/jan_05/article01.htm

[ 5 ] Kingsley Bolton\&David Graddol. English in China Today[J]. English for Global Communicationt,2012(3). 
[ 6 ] Malcolm S Knowles. The Adult Learner [M].London: Routledge ,2012.

[ 7 ] Richard E. Mayer. Applying the Science of Learning:Evidence-Based Principles for the Design of Multimedia Instruction. [J] American Psychologist,2008(11).

[ 8 ] Robert Gagne. The Conditions of Learning [M].Newyork: Holt,Rinehart and Winston,1965.

[ 9 ] Ruth C. Clark and Richard E. Mayer. E-learning and the Science of Instruction [M].Hoboken: John Wiley \& Sons ,2011.

[ 10 ] Susan Ambrose. How Learning Works: Seven Research-Based Principles for Smart Teaching [M].Hoboken: John Wiley \& Sons, 2011.

[ 11 ] Tony Bingham\&Marcia Conner. The New Social Learning: Connect, Collaborate, Work [M].Newyork: ASTD Press, 2015.

[ 12 ] Higher Vocational College English Curriculum Basic Requirement (for Trial Implementation), (2000), p.2.

[ 13 ] Zhang Delu. On Application of Multi-model Theory and Mordern Multi-media Technology toForeign Language Teaching [J].Foreign Language Teaching. 2009, (4). 